\title{
Secondarily Generated Surface Waves in the Tokachi Basin, Hokkaido, Japan
}

\author{
Mitsuko Furumura* and Tsutomu Sasatani \\ Graduate School of Science, Hokkaido University, \\ Kita-ku, Sapporo 060, Japan
}

\begin{abstract}
In order to investigate the site effects of the Tokachi Basin, we have carried out seismic observation at a rock and basin station pair. A comparison of the seismograms observed at the basin site with those at the rock site reveals that later phases having large amplitude and long duration are observed at the basin site even for deep earthquakes. The predominant period of the later phases is 2 to $5 \mathrm{~s}$. We have also carried out the seismic array observations at the basin site, to investigate the propagation characteristics and wave types of these later phases. By application of the semblance and the polarization methods to the seismograms observed in the array, many Rayleigh waves having a phase velocity of about $1.3 \mathrm{~km} / \mathrm{s}$ and a few pure Love waves of about $1 \mathrm{~km} / \mathrm{s}$ are found in the later phases. The arrival directions of these surface waves change quickly with time and are quite different from the backazimuth to the epicenters. This suggests that the later phases observed in the basin site are mainly composed of the surface waves which are generated at the edge surrounding the Tokachi Basin.
\end{abstract}

\section{Introduction}

The seismograms observed in a basin have been investigated to evaluate the site effects of the basin by many researchers (e.g., Tanaka et al., 1979; Minamishima et al., 1986; Frankel et al., 1991; Kinoshita et al., 1992; Yamanaka et al., 1992; Hatayama et al., 1995). These studies have revealed that secondarily generated surface waves originating from body waves or surface waves, which were propagated from epicenters have been observed in the various basins. Zama's review paper (1993) shows that the secondarily generated surface waves have different characteristics in each basin. In the Kanto Basin, dispersing waves having a predominant period of 5 to $10 \mathrm{~s}$ with a large amplitude are observed clearly for shallow earthquakes occurring at the west or south-west of the basin. Kinoshita et al. (1992) revealed that those waves were Love waves excited at the Hachioji tectonic line. In the Osaka Basin, a strong later phase having a predominant period of about $3 \mathrm{~s}$ with amplitude larger than $\mathrm{S}$ wave is seen in the later phases even for deep earthquakes (Hatayama et al., 1995). This phase is interpreted as a Love wave generated at the eastern edge of the basin.

In this study, we investigate the site effects of the Tokachi Basin, Hokkaido,

Received June 2, 1995; Accepted December 28, 1995

* To whom correspondence should be addressed. 


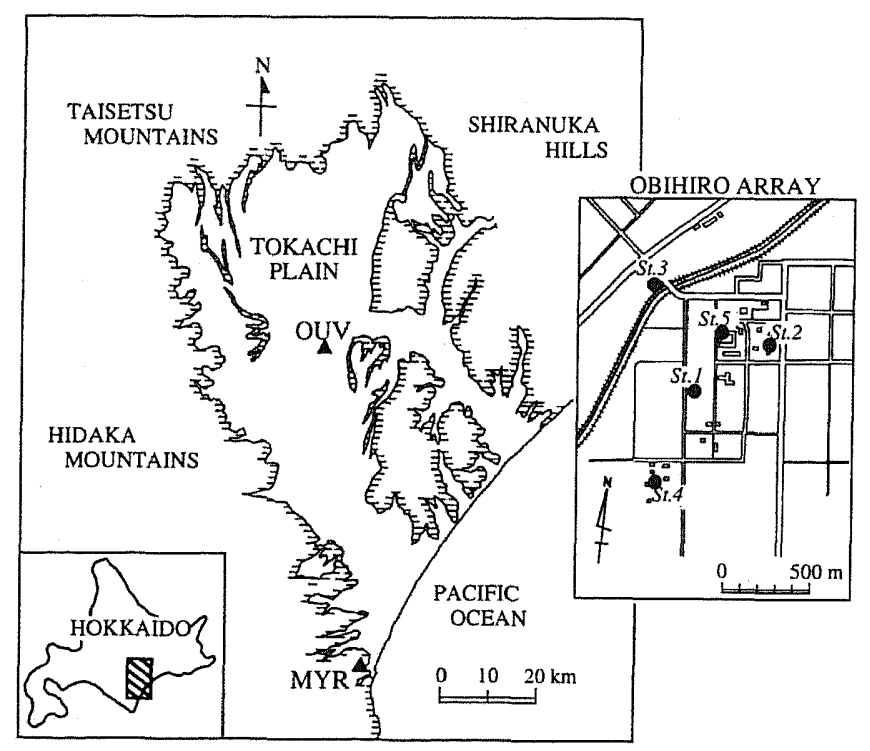

Fig. 1. Station distribution of the seismic observations. MYR is the rock site, and OUV is the basin site. OUV consists of five stations forming a smallaperture array. Hatch denotes the outcrops of the rocks.

Japan. The Tokachi Basin extends about $100 \mathrm{~km}$ in the north-south direction and about $50 \mathrm{~km}$ in the east-west direction, surrounded by the Hidaka Mountains, the Taisetsu Mountains and the Shiranuka Hills (Fig. 1). It is covered with terrace deposits of Pleistocene, and the maximum thickness of the sedimentary layers is about $3,000 \mathrm{~m}$ (Matsushima, 1990). We first compare the seismograms observed at a rock and basin station pair in and around the Tokachi Basin. We show strong excitation of later phases at the basin site for both deep and shallow events. Next, we examine the wave types and propagation characteristics of the later phases. We apply the semblance and the polarization methods to the seismograms which are observed in a dense seismic array at the basin site. Finally, the obtained characteristics of surface waves generated secondarily in the Tokachi Basin are compared with those in the other basins to investigate the localization of the secondarily generated surface waves.

\section{Seismic Observations in and around the Tokachi Basin}

A rock and basin station pair has been operated at Obihiro University (OUV) and at Moyori (MYR), a permanent station of Research Center for Earthquake Prediction of Hokkaido University from 1988 (Fig. 1) (Sasatani et al., 1990). OUV is located near the central part of the Tokachi Basin, and MYR is located at the southern edge on Cretaceous sedimentary rocks and Metamorphic rocks. MYR is about $70 \mathrm{~km}$ south of OUV. The seismograms at MYR provide some information about frequency characteristics and wave types of the incident waves into the basement of the Tokachi 
Basin. Therefore, a comparison between seismograms observed at MYR and those at OUV may reveal the site effects of the Tokachi Basin.

Simultaneously, a dense seismic array observation has been carried out at OUV, in order to examine wave types and propagation characteristics of observed phases in the basin. The array consists of five stations with a diameter of about $1.2 \mathrm{~km}$ (Fig. 1).

At each station, a three-component, velocity-type, strong ground motion seismometer (Muramatu, 1977; Tokyo Sokushin Co.) has been installed. These seismometers have a flat velocity response in the frequency range of 0.002 to $30 \mathrm{~Hz}$ or 0.025 to $20 \mathrm{~Hz}$. The ground motions were recorded by a digital recorder (PDAS-100; Teledyne Co.) at each site individually, with a sampling frequency of $50 \mathrm{~Hz}$ and 16-bit resolution. Clocks of the digital recorders were checked by comparing with the standard electric wave of Japan, JJY, at two- or three-month intervals, so that we kept the time difference among clocks of the five digital recorders in the Obihiro Array to within less than $10 \mathrm{~ms}$.

\section{Observed Seismograms}

Five large earthquakes were selected for this study (Fig. 2, Table 1). Three earthquakes, the Urakawa-Oki, the East off Aomori, and the Eastern Part of Oshima earthquakes, have focal depths of 65 to $121 \mathrm{~km}$ and epicentral distances of 105 to $223 \mathrm{~km}$. In Fig. 3, we compare seismograms observed at MYR with those at OUV for the East off Aomori earthquake. In the seismograms at MYR, S waves predominate and there are no later phases with large amplitude. On the other hand, those observed at OUV have later phases with a large amplitude and long duration. These differences in seismograms observed at two stations indicate the later phases were excited by the Tokachi Basin. Since incident waves into the basement of the Tokachi Basin are confirmed to be body waves for these three events from the small incident angles less than 26 degrees and from the simple seismograms at MYR which are mainly composed of body waves, it is certain that the later phases observed at OUV are basin-induced surface waves (Kawase, 1993). Figure 4 shows instantaneous amplitude spectra of the

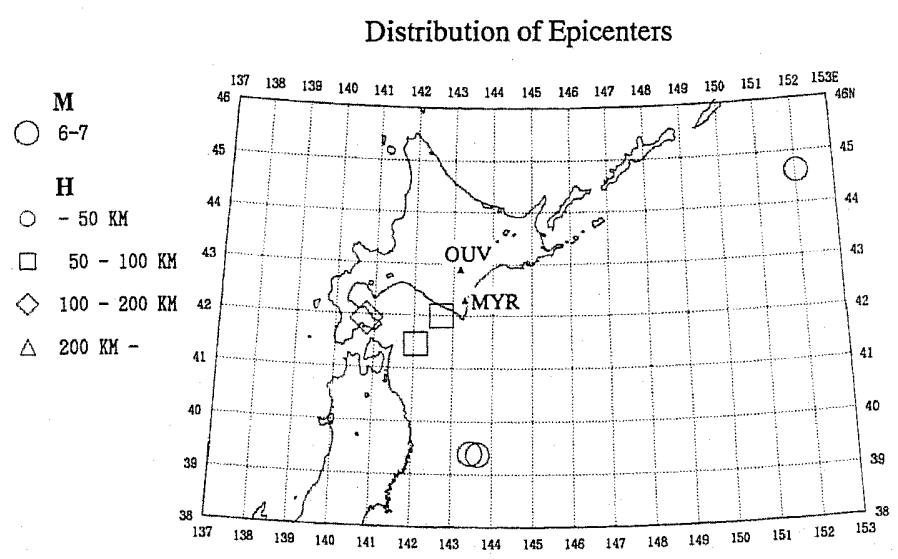

Fig. 2. Epicentral distribution of five earthquakes used in this study.

Vol. 44 , No. 2, 1996 
Table 1. Earthquake source parameters used in this study (after JMA).

\begin{tabular}{cccccccc}
\hline Date & Time & $\begin{array}{c}\text { Latitude } \\
(\mathrm{N})\end{array}$ & $\begin{array}{c}\text { Longitude } \\
(\text { (E) }\end{array}$ & $\begin{array}{c}\text { Depth } \\
(\mathrm{km})\end{array}$ & $M$ & $\begin{array}{c}\Delta \\
(\mathrm{km})\end{array}$ & Epicentral region \\
\hline 91.11 .27 & $04: 40$ & 42.00 & 142.70 & 67 & 6.4 & 105 & Urakawa-Oki \\
91.12 .22 & $17: 44$ & 44.63 & 152.03 & 0 & 6.7 & 737 & Kurile Islands \\
92.07 .12 & $20: 09$ & 41.47 & 142.05 & 65 & 6.3 & 183 & East off Aomori \\
92.07 .18 & $17: 36$ & 39.38 & 143.65 & 0 & 6.9 & 391 & Far East off Sanriku* \\
92.07 .18 & $17: 39$ & 39.40 & 143.43 & 0 & 6.9 & 387 & Far East off Sanriku* \\
92.08 .24 & $15: 59$ & 41.93 & 140.78 & 121 & 6.3 & 223 & Eastern Part of Oshima \\
\hline
\end{tabular}

$A$ denotes epicentral distance for station OUV. * Two events are recorded in one seismogram at MYR and at OUV.
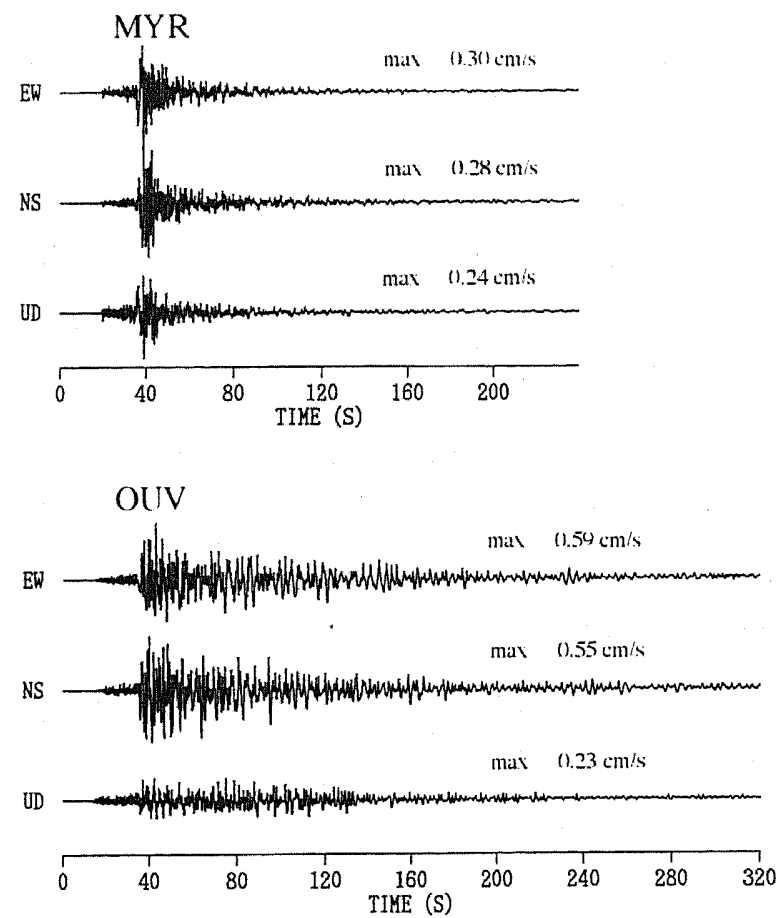

Fig. 3. Observed seismograms at MYR and OUV during the East off Aomori earthquake (Jul. 12, 1992, $M=6.3, H=65 \mathrm{~km}$ ).

seismograms as a function of time and frequency, which are calculated by multiple filter analysis (Dziewonski et al., 1969). The spectra at MYR show large values only at S wave arrival. On the other hand, those at OUV have large values not only at $S$ wave arrival but also at later phase arrivals. The later phases observed at OUV have a predominant frequency in the range of 0.2 to $0.8 \mathrm{~Hz}$ on the horizontal components and in the range of 0.3 to $1.3 \mathrm{~Hz}$ on the vertical component. The seismograms observed at MYR and OUV from the Urakawa-Oki and the Eastern Part of Oshima earthquakes 

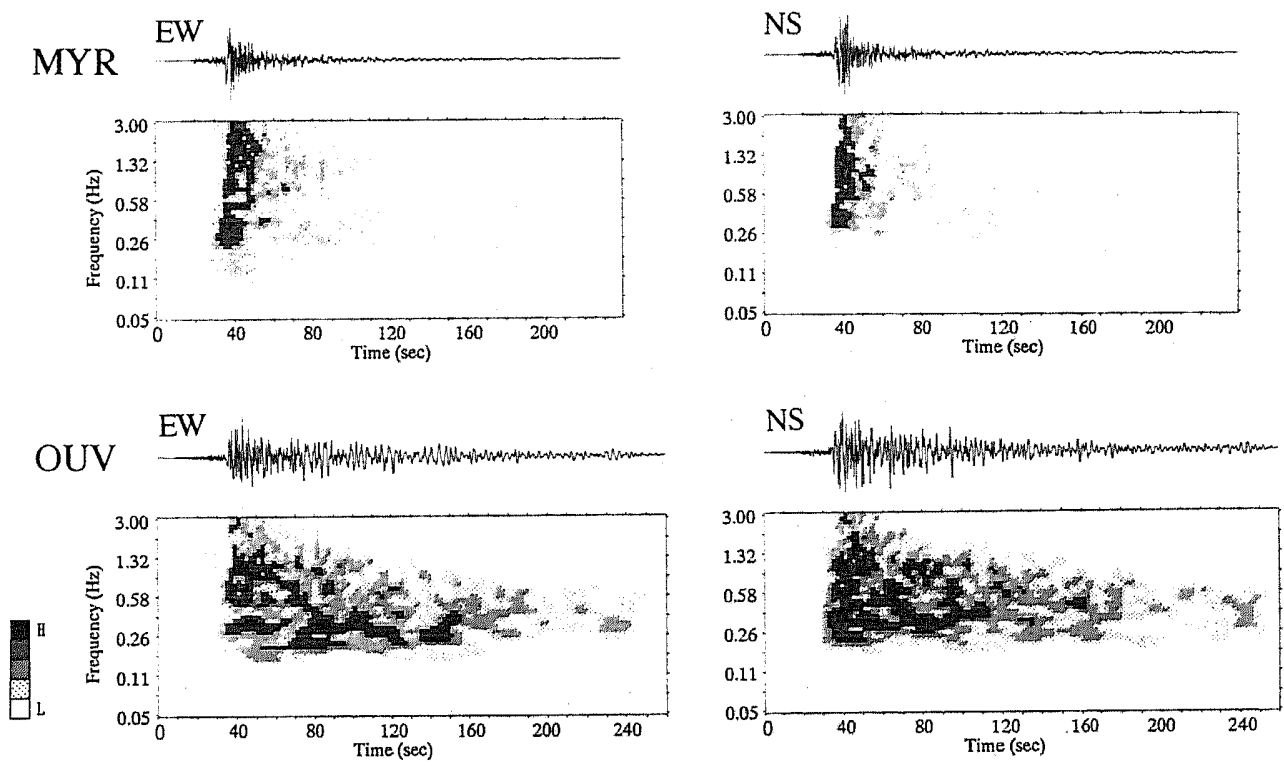

(a)
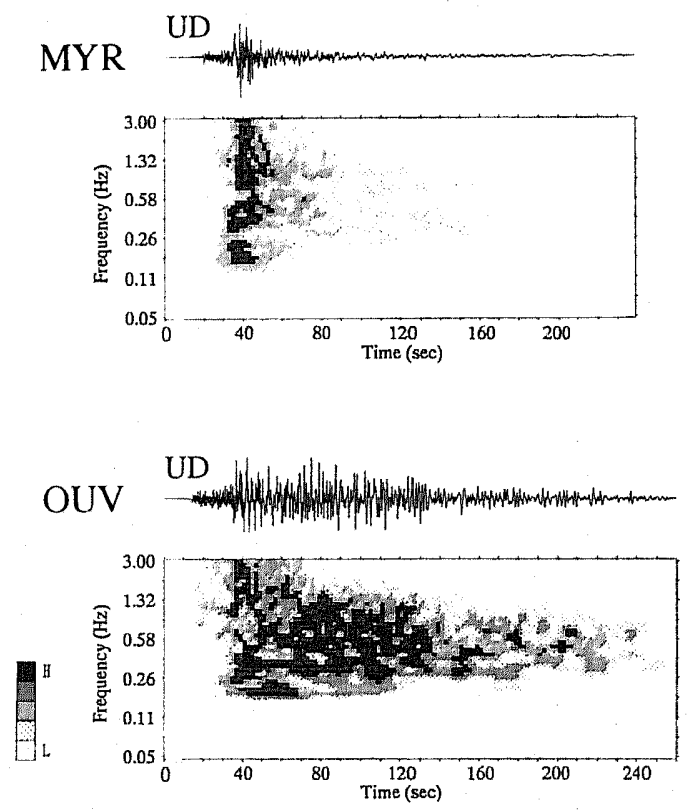

(b)

Fig. 4. Instantaneous amplitude spectra of the observed seismograms at MYR and OUV during the East off Aomori earthquake, which are obtained from multiple filter analysis (Dziewonski et al., 1969). These results are expressed as the logarithm of the ratio of the amplitude to the maximum amplitude and are classified into 5 levels by every $-6 \mathrm{~dB}$.

Vol. 44, No. 2, 1996 

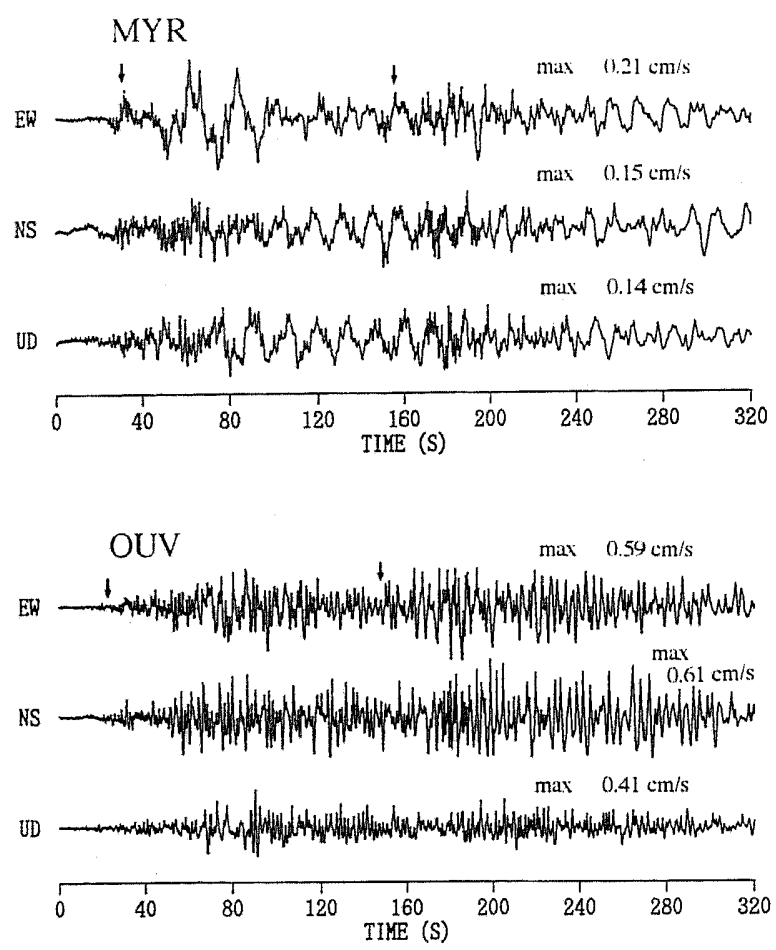

Fig. 5. Observed seismograms at MYR and OUV during the Far East off Sanriku earthquakes (Jul. 18, 1992, $M=6.9, H=0 \mathrm{~km}$ ). These traces include seismograms for two events and the arrow denotes the arrival time of each $\mathrm{S}$ wave.

show the same contrast as mentioned above (Furumura, 1994).

The other two events studied, the Kurile Islands and the Far East off Sanriku earthquakes, are shallow events. They have a long epicentral distance of more than $387 \mathrm{~km}$ for OUV, and surface waves must be predominant in the incident waves into the Tokachi Basin. In Fig. 5, we show seismograms observed at MYR and OUV for the Far East off Sanriku earthquakes, which include two events. Since great circles passing MYR and OUV are almost overlapped between hypocenters and MYR, we can consider that the seismograms at MYR for these events as the incident waves into the Tokachi Basin and that differences in seismograms between MYR and OUV expresses the strength of site effects of the Tokachi Basin on the seismograms (Fig. 2). In the seismograms at MYR, the waves of 10- to 20-s period predominate, which are probably surface waves propagated from the epicenters. On the other hand, short period waves of 2 to $5 \mathrm{~s}$ are dominant in the seismograms at OUV. Figure 6 shows Fourier amplitude spectra calculated from the whole seismogram on each component. The spectra at OUV have peaks in the frequency range of 0.1 to $0.7 \mathrm{~Hz}$ and in the frequency range of 0.02 to $0.08 \mathrm{~Hz}$. The amplitude of the former peak is greater than the amplitude level at MYR by a factor of about 10. This indicates that the later phases having the predominant frequency of 0.1 to $0.7 \mathrm{~Hz}$ observed at OUV are basin-transduced surface 
MYR
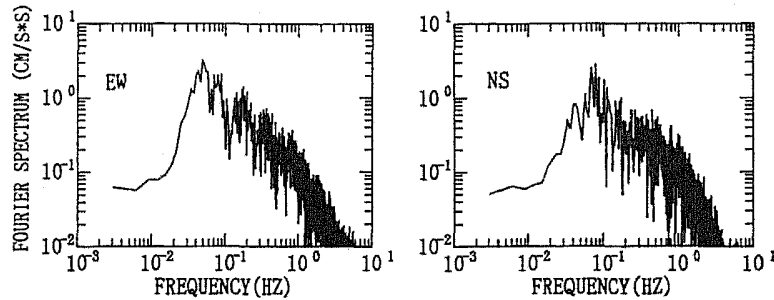

OUV

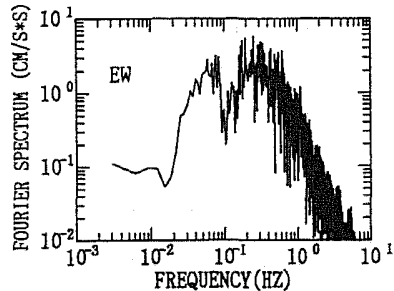

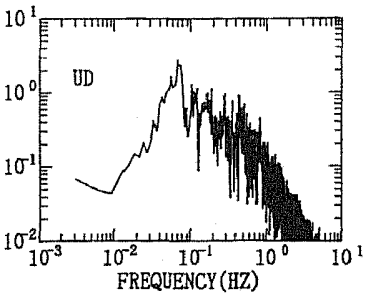

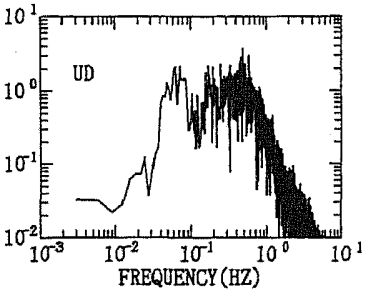

Fig. 6. Fourier amplitude spectra of the seismograms at MYR and OUV for the Far East off Sanriku earthquakes.

waves (Kawase, 1993). The lower predominant frequency at OUV corresponds to a peak in the spectra at MYR, and the amplitude level of the both peaks is nearly the same. This means that the long period waves observed at MYR propagate to OUV through the Tokachi Basin without any modification. The seismograms observed at MYR and OUV from the Kurile Islands earthquake also show the same contrast as mentioned above (Furumura, 1994).

Inspecting the seismograms at MYR and OUV for five events, we conclude that the seismic response of the Tokachi Basin is characterized by later phases having large amplitude and long duration which are observed for both body wave incidence and surface wave incidence and by their predominant frequency of 0.1 to $1.3 \mathrm{~Hz}$.

\section{Propagation Characteristics of Later Phases}

In order to examine the propagation characteristics and wave types of the later phases, we filtrated the seismograms at the Obihiro Array with a bandpass filter having central frequency at 0.4 or $0.5 \mathrm{~Hz}$. The Gaussian function, $H(f)=\exp (-3.38$ $\left.\times\left(\left(f-f_{\mathrm{c}}\right) / f_{\mathrm{c}}\right)^{2}\right)\left(f_{\mathrm{c}}\right.$ : the central frequency), was used as a transfer function of the filter.

\subsection{Vertical components}

The semblance method (Neidell and Taner, 1971) was applied to the seismograms observed in the Obihiro Array for examination of arrival directions, apparent velocities, and semblance values of the later phases on the vertical components. The semblance value in a time window indicates coherency among the waveforms observed at stations 

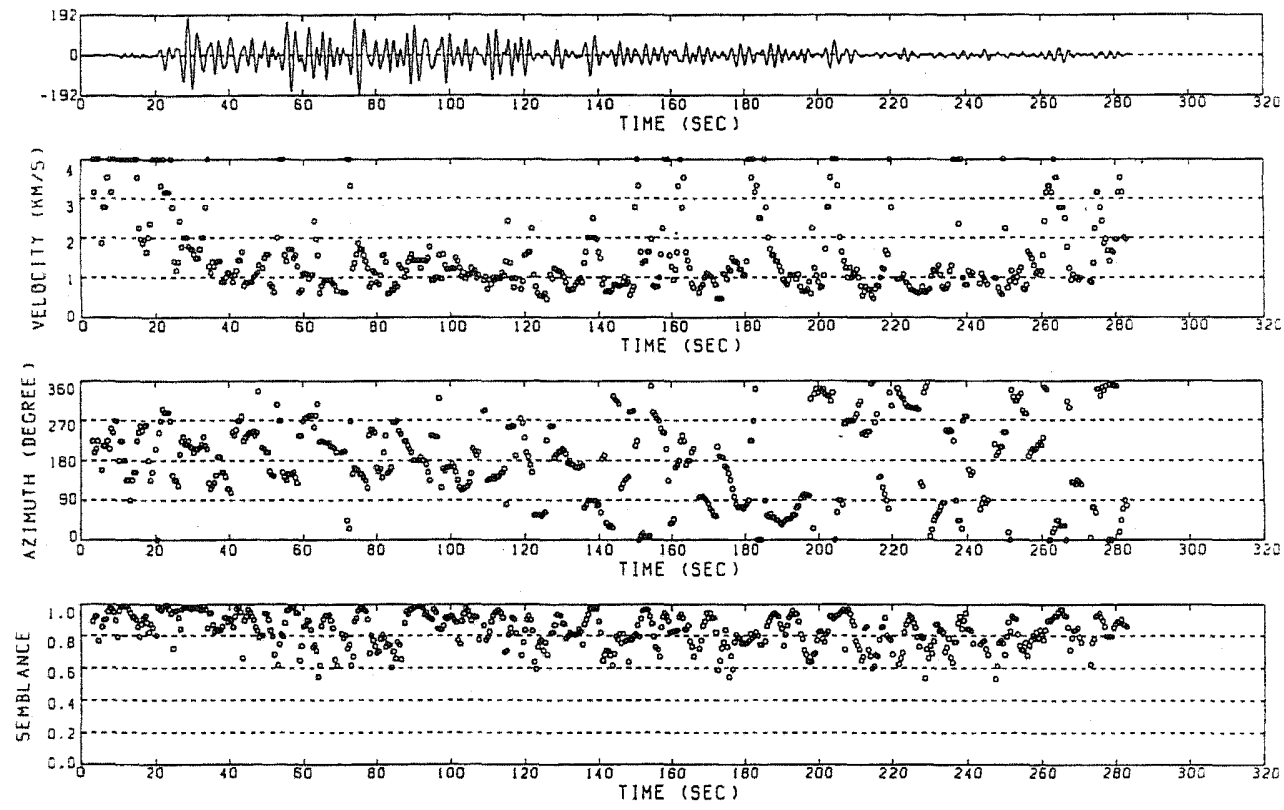

Fig. 7. Apparent velocities, arrival directions and semblance values obtained from semblance analysis of the vertical-component seismograms for the East off Aomori earthquake. Top shows one of the vertical-component seismograms in the array. Apparent velocity of more than $4 \mathrm{~km} / \mathrm{s}$ is plotted as $4 \mathrm{~km} / \mathrm{s}$, because the high apparent velocity is not so reliable. Arrival directions are measured in degrees clockwise from north.

in that window. It becomes low when coherent waves are not observed in the array or when the observed wave train contains more than one kind of wave (different wave type or different arrival direction). In this study, we used time windows whose window length is equal to one-half of the inverse of the central frequency of the bandpass filter used. The apparent velocities and arrival directions of the waves are poorly determined by our array arrangement when the apparent velocities are more than $4 \mathrm{~km} / \mathrm{s}$, because the wavelength of such waves is much larger than the diameter of the Obihiro Array which is about $1.2 \mathrm{~km}$. We regard the later phases as Rayleigh waves if the observed apparent velocities are similar to the theoretical Rayleigh-wave phase velocities which are calculated based on the velocity structure at OUV.

Figure 7 shows an example of the apparent velocities, arrival directions, and semblance values obtained from vertical-component seismograms for the East off Aomori earthquake. During the time of 3 to $22 \mathrm{~s}$, in which direct S-waves are included, apparent velocities are more than $4 \mathrm{~km} / \mathrm{s}$. On the other hand, many later phases after $\mathrm{S}$ arrival have low apparent velocities of about $1 \mathrm{~km} / \mathrm{s}$. The arrival directions of these waves are quite different from the backazimuth to the epicenter. Semblance values are 

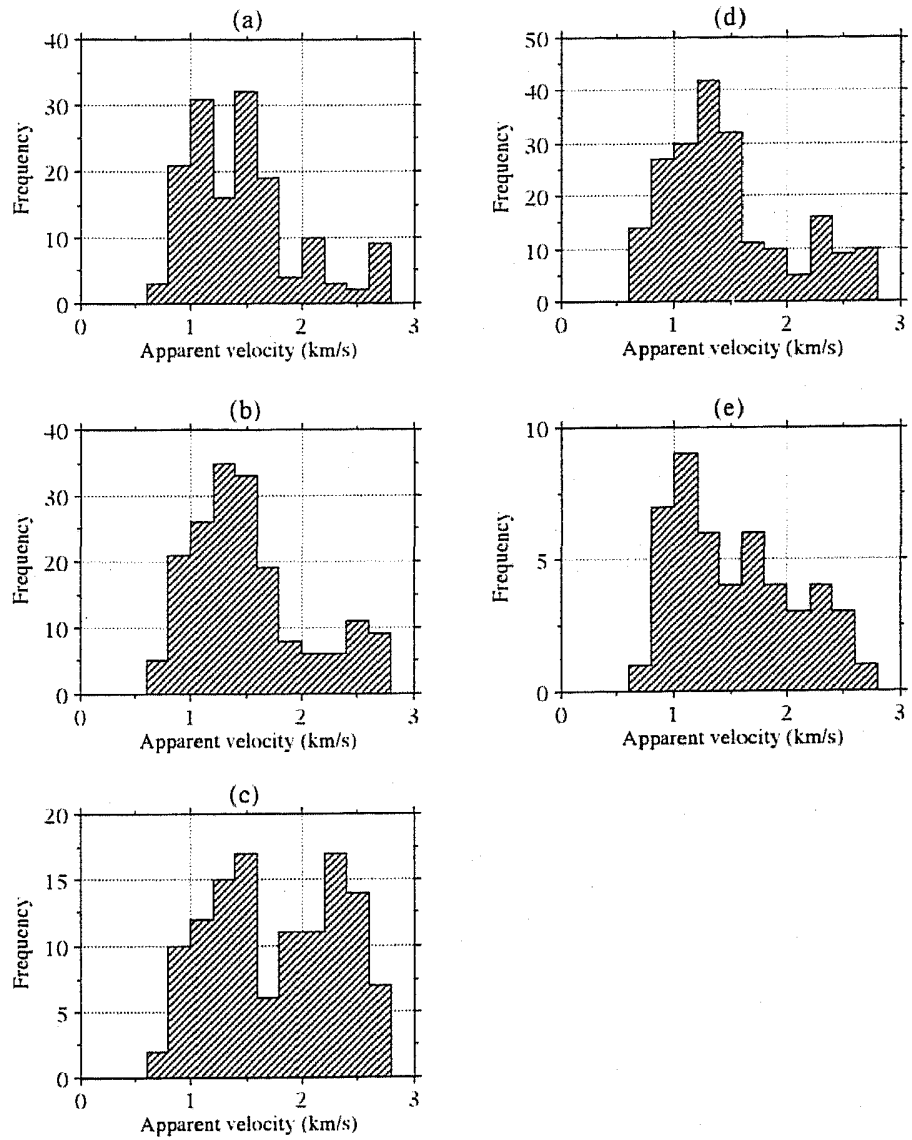

Fig. 8. Histograms for the apparent velocities of the later phases on vertical components which have semblance values of more than 0.9. (a) The East off Aomori earthquake. (b) The Urakawa-Oki earthquake. (c) The Eastern part of Oshima earthquake. (d) The Far East off Sanriku earthquakes. (e) The Kurile Islands earthquake.

more than 0.9 for many waves.

The waves having low apparent velocities are also observed for other four events. Figure 8 shows histograms for apparent velocities of the waves whose semblance values are larger than 0.9 . The histograms looks like a normal distribution which have a peak at about $1.3 \mathrm{~km} / \mathrm{s}$ and deviation of about $0.6 \mathrm{~km} / \mathrm{s}$, except for the Eastern Part of Oshima earthquake. Since body wave would have an apparent velocity larger than $3.0 \mathrm{~km} / \mathrm{s}$, those waves are considered as Rayleigh waves. For the Eastern Part of Oshima earthquake, the histogram shows a peak at $2.3 \mathrm{~km} / \mathrm{s}$ as well as a peak at $1.5 \mathrm{~km} / \mathrm{s}$. The difference between higher apparent velocity and lower apparent velocity is significant, and it may suggest two modes of Rayleigh waves.

In Fig. 9, we compare the center value and deviation of the obtained apparent

Vol. 44, No. 2, 1996 


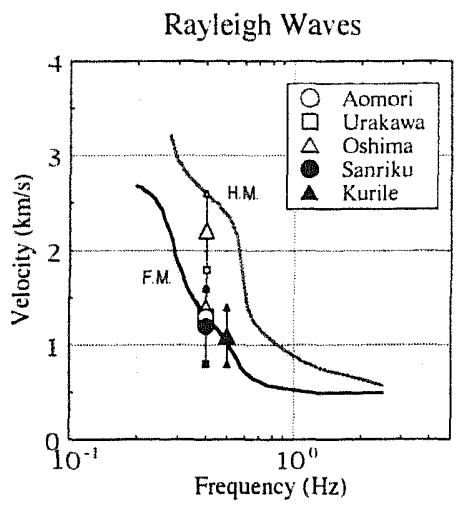

Fig. 9. Comparison of the phase velocities of the later phases for five events with theoretical dispersion curves of the phase velocity of the Rayleigh waves. F.M., fundamental mode; H.M., higher mode.

Table 2. Velocity and density structures at OUV (after Matsushima, 1990).

\begin{tabular}{ccccc}
\hline Layer & $V_{\mathrm{P}}(\mathrm{km} / \mathrm{s})$ & $V_{\mathrm{S}}(\mathrm{km} / \mathrm{s})$ & $\rho\left(\mathrm{g} / \mathrm{cm}^{3}\right)$ & Thickness $(\mathrm{km})$ \\
\hline 1 & 1.89 & 0.50 & 1.88 & 0.30 \\
2 & 2.12 & 0.73 & 1.98 & 0.33 \\
3 & 4.88 & 2.80 & 2.52 & 1.90 \\
4 & 5.56 & 3.20 & 2.62 & \\
\hline
\end{tabular}

velocities with theoretical dispersion curves for the phase velocity of Rayleigh waves. The theoretical dispersion curves are calculated based on the velocity structure at OUV (Table 2). The apparent velocities for five events are almost identical with the phase velocities of fundamental Rayleigh waves. Therefore, we conclude that the later phases with semblance values higher than 0.9 and apparent velocities less than $1.8 \mathrm{~km} / \mathrm{s}$ on the vertical-component seismograms are fundamental Rayleigh waves. The velocity of $2.3 \mathrm{~km} / \mathrm{s}$ observed for the Eastern Part of Oshima earthquake is nearly the same as the theoretical phase velocities of the first higher mode of Rayleigh waves.

The arrival directions of the later phases, which are considered as fundamental Rayleigh waves, are shown in Fig. 10 as a function of time to see their propagation characteristics. The arrival directions of the Rayleigh waves change quickly with time and many of them are quite different from the backazimuth to the epicenter. The disagreement between arrival directions of the Rayleigh waves and the backazimuth to the epicenter would suggest that these Rayleigh waves are secondarily generated at the edge surrounding the Tokachi Basin. For two shallow earthquakes, the difference may arise from a multi-path effect due to a heterogeneous structure. However, this effect alone cannot explain the fact that many surface waves are observed at OUV in succession with much larger amplitude than those at MYR. 
(a)

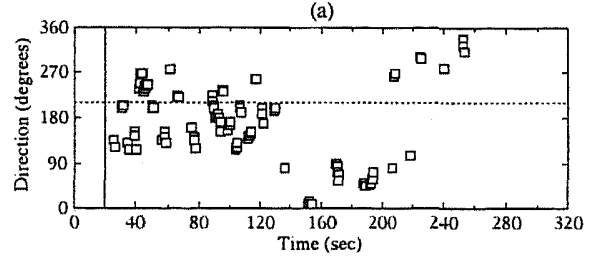

(b)

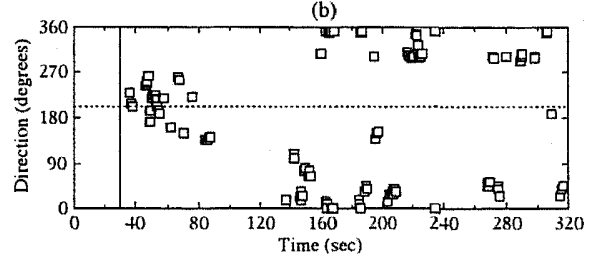

(c)

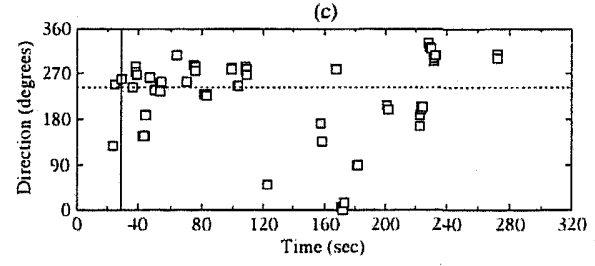

(d)

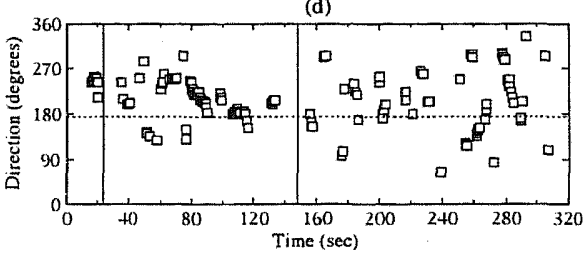

(e)

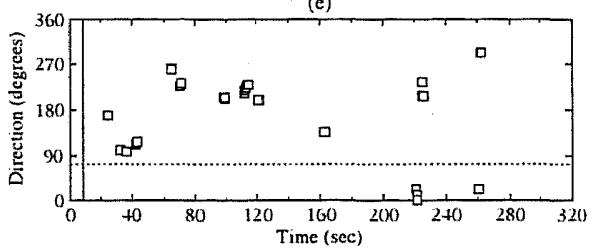

Fig. 10. Arrival directions of the later phases which have apparent velocities of less than $1.8 \mathrm{~km} / \mathrm{s}$. Dotted line and solid line denote the backazimuth to the epicenter and arrival time of $S$ wave, respectively. (a) The East off Aomori earthquake. (b) The Urakawa-Oki earthquake. (c) The Eastern part of Oshima earthquake. (d) The Far East off Sanriku earthquakes. (e) The Kurile Islands earthquake.

\subsection{Horizontal components}

We also investigated the propagation characteristics of the later phases on the horizontal-component seismograms using semblance analysis. At this time, it is indispensable to examine the polarization characteristics of the waves for discrimination of Love waves from Rayleigh waves observed on the horizontal components. Then the polarization parameters, that is, polarization direction, dip, elliptical component of polarization $P_{\mathrm{E}}$, polarization strength $P_{\mathrm{S}}$, were calculated using the complex polarization analysis (Vidale, 1986). The elliptical component of polarization $P_{\mathrm{E}}$ means rectilinearlity of the ellipse: $P_{\mathrm{E}}$ is 0 when the ground motion polarized linearly, and $P_{\mathrm{E}}$ is 1 when the ground motion polarized circularly. The polarization strength $P_{\mathrm{S}}$ is defined as the parameter that indicates the reliability of the other three polarization parameters. A polarization strength $P_{\mathrm{S}}$ of 1 means that the particle motion is expressed by an ellipse completely. For a long time window, analyzed seismograms will include more than one kind of polarization mode, then, the parameter $P_{\mathrm{S}}$ closes to 0 because the polarization is not expressed by one ellipse. In this study, the polarization method is applied to the seismograms for time windows whose window length is equal to the inverse of the central frequency of the bandpass filter used.

By applying the polarization method to the later phases, we can select the phases 


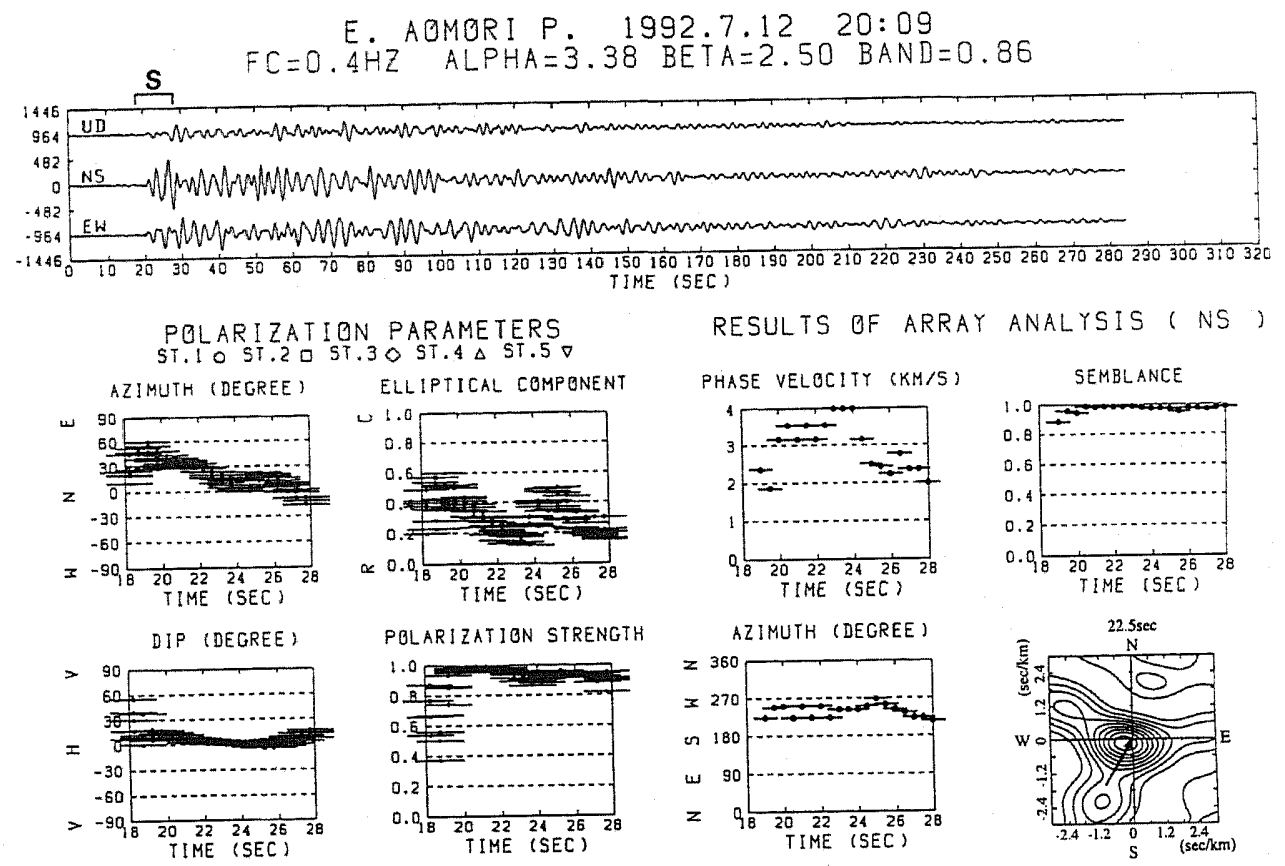

Fig. 11. Various parameters obtained from the semblance and polarization analyses of the S-wave portion for the East off Aomori earthquake. The semblance method is applied to the NS-component seismograms. The counter map in the lower right corner shows semblance value as a function of the horizontal slowness and the arrow in it denotes the epicenter-to-station azimuth.

that are linearly polarized in a horizontal plane. Next, the wave type of the later phases is inferred from the apparent velocity and the arrival direction, which are obtained by application of the semblance method to selected waves, and from the polarization direction.

Previous to the semblance and polarization combined analyses of the horizontalcomponent later phases, we apply the method to the S-wave portion to make a criterion for selection of the pure waves which are linearly polarized in a horizontal plane (Fig. 11 ). Around $23 \mathrm{~s}$, the polarization strength $P_{\mathrm{S}}$ is more than 0.9 , the elliptical component $P_{\mathrm{E}}$ is less than 0.3 , and the dip is about 0 . From the semblance analysis of NS-component seismograms observed in the array, it is found that the apparent velocity is more than $4 \mathrm{~km} / \mathrm{s}$ and that the arrival direction is WSW, which is nearly in agreement with the backazimuth to the epicenter. Then we can regard the analyzed waves as direct $\mathrm{S}$ waves. Referring to the results of this test, we regard the ground motion as linearly polarized waves in a horizontal plane if the polarization strength $P_{\mathrm{S}}$ is more than 0.9 , the elliptical component $P_{\mathrm{E}}$ is less than 0.3 , and the dip is about 0 .

Figure 12 shows averages and standard deviations of polarization parameters for the East off Aomori earthquake, which were obtained from the seismograms at five 

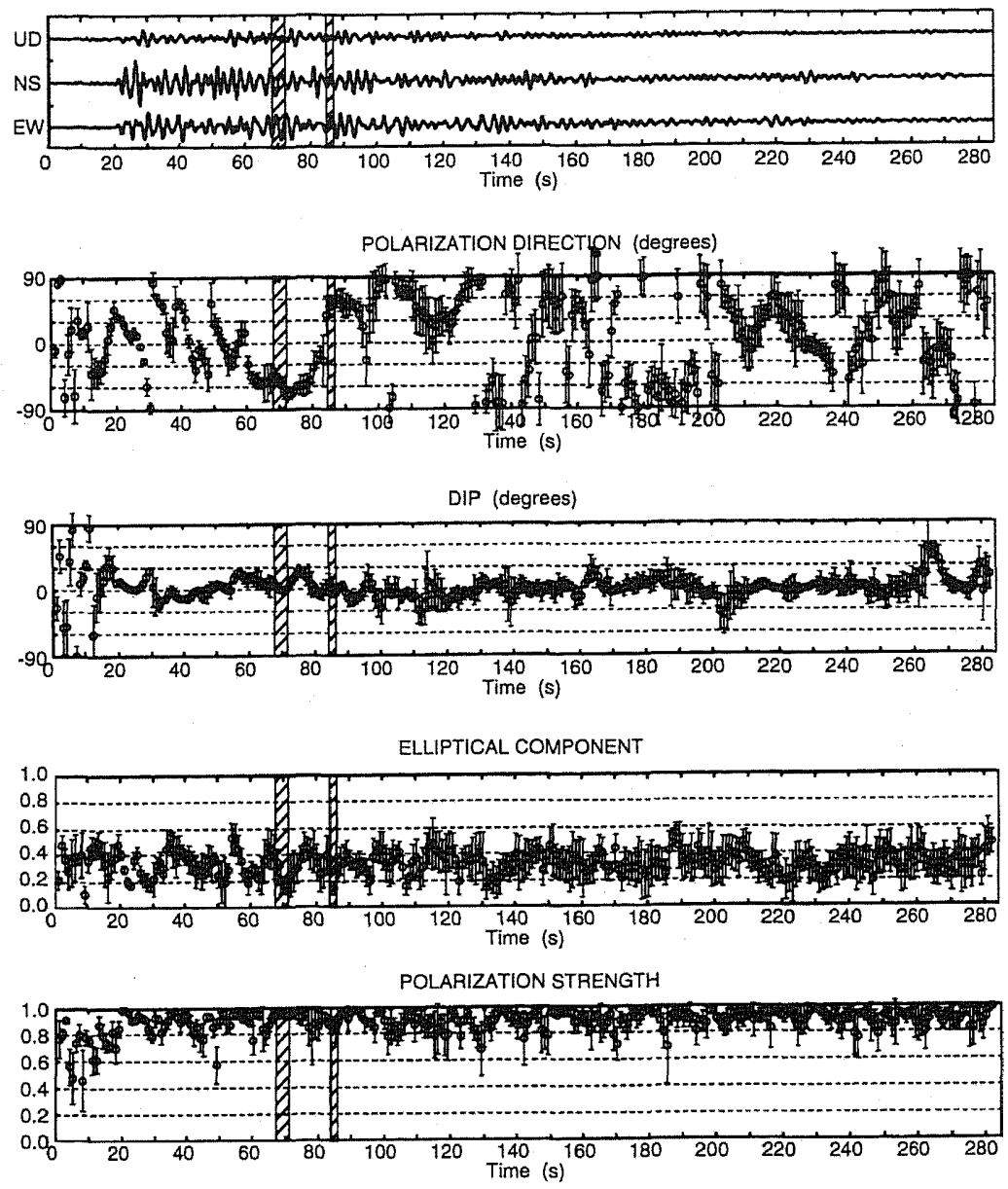

Fig. 12. Averages and standard deviations of obtained polarization parameters from five three-component seismograms for the East off Aomori earthquake. Shaded areas denote the waves which have linear polarization in a horizontal plane. Top shows three-component seismograms observed at one of the array stations.

stations in the Obihiro Array. Although the polarization strength $P_{\mathrm{S}}$ is more than 0.9 in about $50 \%$ of the time windows, only two wave trains satisfied the above criterion of linear polarization in a horizontal plane. From semblance analysis of the wave trains on east-west components, it is found that the wave train around $70 \mathrm{~s}$ have an apparent velocity of about $1 \mathrm{~km} / \mathrm{s}$ and have an arrival direction of SSW (Fig. 13). The arrival direction is nearly perpendicular to the polarization direction of NW-SE. The low apparent velocity and the approximate perpendicularity between the arrival direction and the polarization direction suggest that this wave is a pure Love wave.

In a similar way, 12 wave trains were detected as pure Love waves from seismograms

Vol. 44, No. 2, 1996 


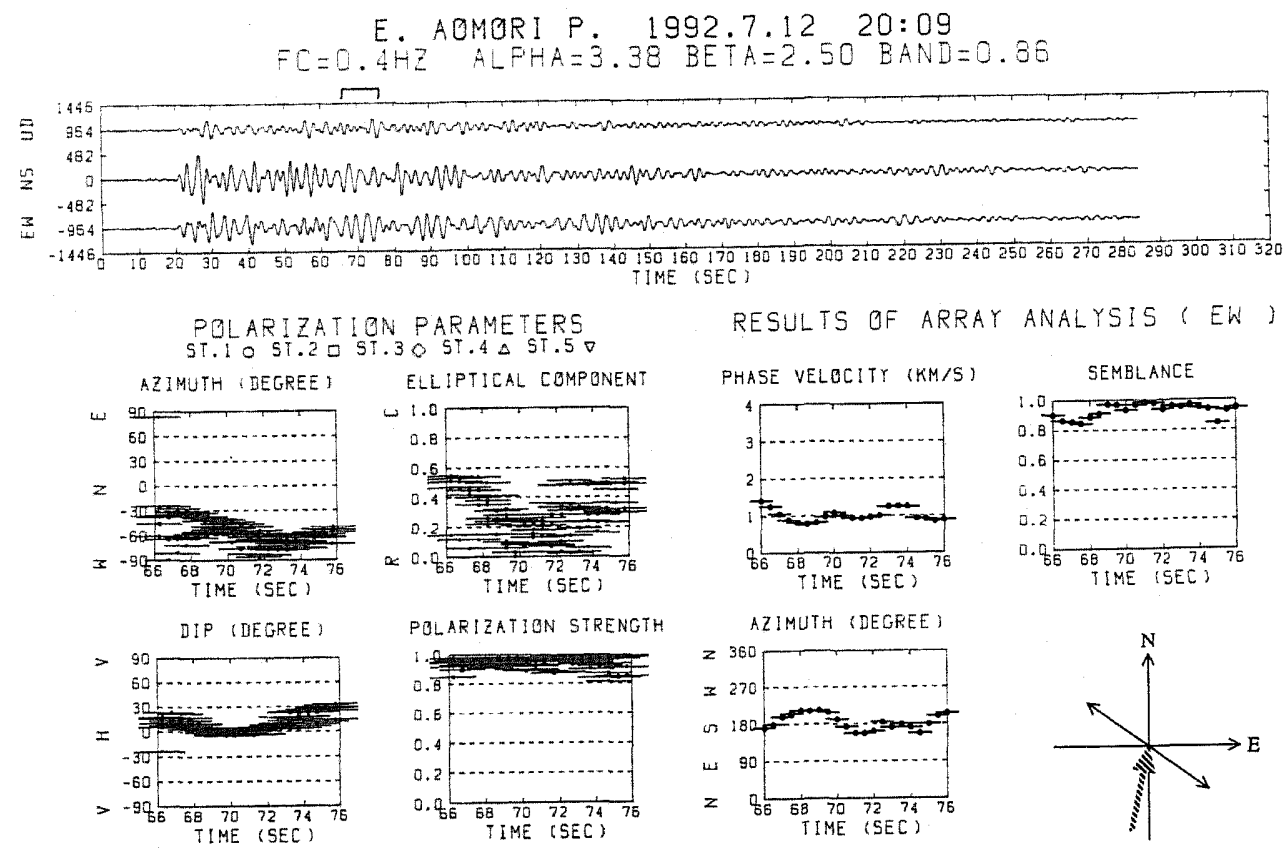

Fig. 13. An example of the various parameters obtained from the semblance and polarization analyses for linearly polarized waves in a horizontal plane during the East off Aomori earthquake. The arrival direction (thick arrow) is almost perpendicular to the polarization direction (thin arrow). Time window is denoted in top.

for four events. No pure Love waves were detected from the seismograms observed in the Obihiro Array for the Kurile Islands earthquake. Phase velocities of these pure Love waves are in the range of 0.5 to $2 \mathrm{~km} / \mathrm{s}$ and they are almost identical with the theoretical phase velocities of fundamental Love waves, which are calculated based on the velocity structure at OUV (Fig. 14). The predominant frequency of detected Love waves is about $0.3 \mathrm{~Hz}$ and it corresponds to the frequency of Airy phase. The arrival directions of some observed Love waves disagree with the backazimuth to the epicenters (Fig. 15). Therefore, we can conclude that the detected waves are the pure Love waves generated at the edge of the Tokachi Basin.

The secondarily generated Rayleigh waves are detected in many time windows on the vertical components, while few pure Love waves are detected on the horizontal components. One of the reasons why few pure Love waves were detected may be the contamination of Love wave ground motion by horizontal components of the Rayleigh waves. Although few pure Love waves were detected, we believe that many secondarily generated Love waves are included on the horizontal components. 
Love Waves

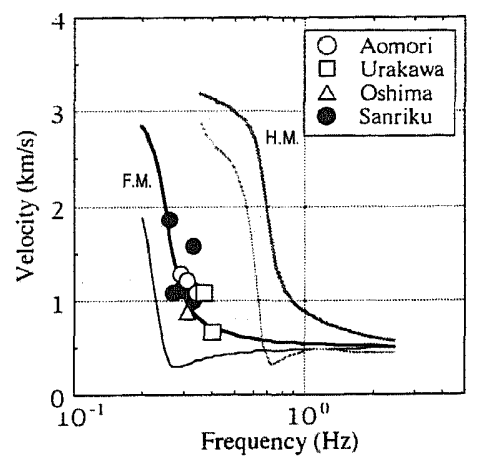

Fig. 14. Comparison of phase velocities of the detected Love waves with theoretical dispersion curves of the Love waves. Thick and thin lines denote the dispersion curve of the phase velocity and that of the group velocity, respectively. F.M., fundamental mode; H.M., higher mode.

(a)

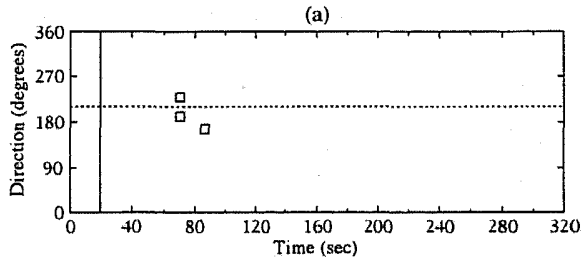

(b)

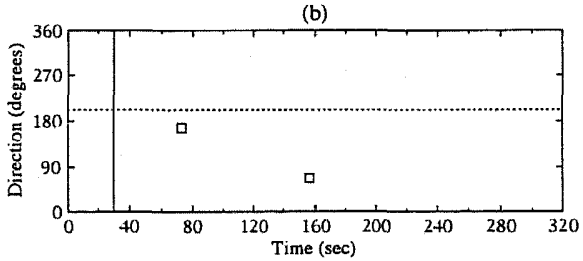

(c)
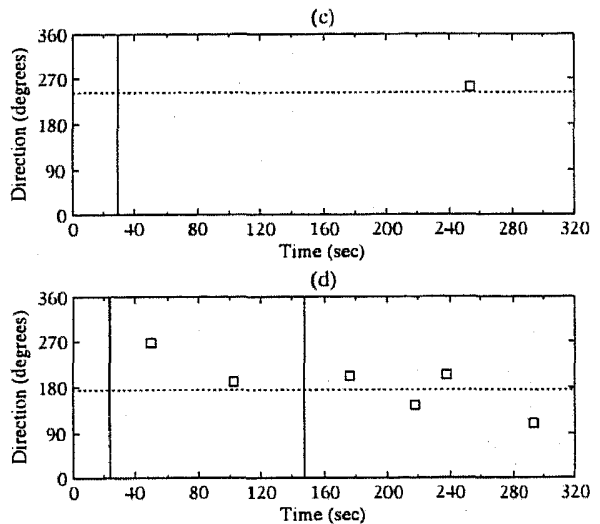

Fig. 15. Arrival directions of the detected Love waves. Dotted line and solid line denote the backazimuth to the epicenter and arrival time of $S$ wave, respectively. (a) The East off Aomori earthquake. (b) The Urakawa-Oki earthquake. (c) The Eastern part of Oshima earthquake. (d) The Far East off Sanriku earthquakes.

\section{Discussion}

The arrival directions of fundamental Rayleigh waves for the East off Aomori earthquake show a large change at about $100 \mathrm{~s}$ after the $S$ wave arrival (Fig. 10). Many Rayleigh waves generated by the Tokachi Basin arrive at the Obihiro Array from the south, the southeast, or the southwest during about $100 \mathrm{~s}$ after the $\mathrm{S}$ waves. The backazimuth to the epicenter is included in that azimuth range. After that duration, many Rayleigh waves come from the north, the northeast, or the northwest. This change in arrival directions suggests that the Rayleigh waves are generated at the northern

Vol. 44, No. 2, 1996 
edge of the Tokachi Basin and that it takes a long time for these waves to arrive at the Obihiro Array. It probably reflects the geometry of the Tokachi Basin, which have a long axis in the north-south direction. A similar change in the arrival directions of Rayleigh waves are also seen for the Urakawa-Oki, the Eastern Part of Oshima, and the Kurile Islands earthquakes. At nearly the same moment that the arrival directions of the later phases change significantly, the amplitude of the waves become less than a half. This may indicate that the Rayleigh waves observed in later time windows propagate a longer distance, resulting in stronger attenuations along the path. In the case of the Far East off Sanriku earthquakes, we cannot see the above change in the arrival directions of the Rayleigh waves. This may happen by the superposition of later phases for the second event on those for the first event.

Phillips et al. (1993) have revealed that basin-induced surface waves observed in the Kanto Basin with a predominant period of about $1 \mathrm{~s}$ were excited at the western edge of the basin, where the distance from the station to the boundary of the basin is the shortest. However, the arrival directions of secondarily generated surface waves observed in the Tokachi Basin do not depend on geography of the basin: the west and the east edge of the Tokachi Basin are much closer to the Obihiro Array than the north and the south edge, but many surface waves are propagated from the south with large amplitude. This suggests that the excitation of the surface waves is related to the backazimuth, to the epicenters, and to the three-dimensional basin structure.

Next, we will discuss briefly the localization of secondarily generated surface waves, comparing characteristics of the secondarily generated surface waves observed in the Tokachi Basin with those in the Kanto and Osaka Basins.

A main difference in the site response between the Kanto Basin and the Tokachi Basin is the predominant period of the secondarily generated surface waves. In the Kanto Basin, Love waves with a predominant period of 5 to $10 \mathrm{~s}$ are observed clearly with large amplitude as basin-transduced surface waves. On the other hand, in the Tokachi Basin, many Rayleigh waves having a predominant period of about $3 \mathrm{~s}$ are observed with a large amplitude for both deep and shallow earthquakes. The basin size and the shape ratio, i.e. the ratio of the maximum sediment thickness to the valley half-width, are $150 \mathrm{~km}$ by $150 \mathrm{~km}$ and $4 / 75$ for the Kanto Basin (Koketsu and Higashi, 1992), and $50 \mathrm{~km}$ by $100 \mathrm{~km}$ and $3 / 25$ for the Tokachi Basin (Matsushima, 1990). Therefore, the difference in the predominant period between two basins is probably related to the shape ratio and the size of the basin.

The main difference between the Osaka Basin and the Tokachi Basin is the quality of surface wave generation. In the Osaka Basin, a prominent later phase having large amplitude with a predominant period of about $3 \mathrm{~s}$ is observed for deep earthquakes (Hatayama et al., 1995). On the other hand, such prominent later phases are not seen in the Tokachi Basin, but many later phases having nearly the same amplitude are observed with a short break or are superposed. Excitation of the strong later phase observed in the Osaka Basin is related to the eastern edge where the slope of the basement is much steeper than that at the other parts of the edge surrounding the Osaka Basin (Toriumi et al., 1990). This kind of structure does not exist in the Tokachi Basin. In addition, velocity contrast of the overlaying sedimentary layer and the basement (1.4 to 3.3 for the Osaka Basin and 1.4 to 2.8 for the Tokachi Basin) may be related to 
the difference in surface-wave excitation between the Osaka Basin and the Tokachi Basin.

\section{Conclusions}

The site effects of the Tokachi Basin were investigated by comparing the seismograms observed at the basin site with those at the rock site. The wave types and the propagation characteristics of later phases observed at the basin site were also studied. The waves having a predominant period of about 2 to $5 \mathrm{~s}$ are strongly affected by the Tokachi Basin, and the basin-induced and the basin-transduced surface waves with these predominant periods are observed at the basin site with large amplitude and long duration. From the semblance and polarization analyses, many Rayleigh waves and a few pure Love waves were found in the seismograms observed at the basin site. The arrival directions of these surface waves are quite different from the backazimuth to the epicenters, which suggests that these waves are generated at the edge surrounding the Tokachi Basin.

We thank Prof. T. Koyanagi, Obihiro University, for his help with the installation and maintenance of the observation system. We also thank Dr. T. Moriya, Hokkaido University, and Dr. T. Matsushima, Kyushu University, for their help with the construction of the observation system. Prof. F. Tsuchiya, Obihiro University, the staff of Obihiro University and the staff of Obihiro City permitted us to install observation sites. The calculations were carried out by HITAC M-680H at the Center for Information Processing Education of Hokkaido University. Comments made by two anonymous reviewers were useful for improvement of the manuscript.

\section{REFERENCES}

Dziewonski, A., S. Bloch, and M. Landisman, A technique for the analysis of transient seismic signals, Bull. Seismol. Soc. Am., 59, 427-444, 1969.

Frankel, A., S. Hough, P. Friberg, and R. Busby, Observations of Loma Prieta aftershocks from a dense array in Sunnyvale, California, Bull. Seismol. Soc. Am., 81, 1900-1922, 1991.

Furumura, M., A study on the long-period seismic response of the Tokachi plain, Ph. D. thesis, Hokkaido University, 143 pp., 1994 (in Japanese).

Hatayama, K., K. Matsunami, T. Iwata, K. Irikura, Basin-induced Love waves in the eastern part of the Osaka basin, J. Phys. Earth, 43, 131-155, 1995.

Kawase, H., Review: Amplification of seismic waves by sedimentary layers and its simulation, Zisin (J. Seismol. Soc. Jpn.), 46, 171-190, 1993 (in Japanese with English abstract).

Kinoshita, S., H. Fujiwara, T. Mikoshiba, and T. Hoshino, Secondary Love waves observed by a strong-motion array in the Tokyo lowlands, Japan, J. Phys. Earth, 40, 99-116, 1992.

Koketsu, K. and S. Higashi, Three-dimensional topography of the sediment/basement interface in the Tokyo metropolitan area, central Japan, Bull. Seismol. Soc. Am., 82, 2328-2349, 1992.

Matsushima, T., Studies on determination of deep geological structures using long-period microtremors, Ph. D. thesis, Hokkaido University, 133 pp., 1990 (in Japanese with English abstract).

Minamishima, M., K. Yamazaki, and K. Kudo, A preliminary analysis of wave groups found

Vol. 44, No. 2, 1996 
in the strong ground motion records observed on sedimentary layers, Zisin (J. Seismol. Soc. Jpn.), 39, 533-554, 1986 (in Japanese with English abstract).

Muramatu, I., A velocity type strong motion seismograph with wide frequency range, Zisin ( $J$. Seismol. Soc. Jpn.), 30, 317-338, 1977 (in Japanese with English abstract).

Neidell, N. S. and M. T. Taner, Semblance and other coherency measures for multichannel data, Geophysics, 36, 482-497, 1971.

Phillips, W. S., S. Kinoshita, and H. Fujiwara, Basin-induced Love waves observed using the strong-motion array at Fuchu, Japan, Bull. Seismol. Soc. Am., 83, 64-84, 1993.

Sasatani, T., T. Matsushima, and T. Koyanagi, Observations of strong motion in and around the Tokachi plain, Geophys. Bull. Hokkaido Univ., 54, 15-22, 1990 (in Japanese with English abstract).

Tanaka, T., S. Yoshizawa, and Y. Osawa, Characteristics of strong earthquake ground motion in the period range from 1 to 15 seconds - Analysis of the low-magnification seismograph records-, Bull. Earthq. Res. Inst., Univ. Tokyo, 54, 629-655, 1979 (in Japanese with English abstract).

Toriumi, I., Y. Takeuchi, S. Ohba, M. Horike, Y. Inoue, and K. Baba, Underground structure in the Osaka plain —by Hokko explosions (1988)—, Zisin (J. Seismol. Soc. Jpn.), 43, 373-378, 1990 (in Japanese with English abstract).

Vidale, J. E., Complex polarization analysis of particle motion, Bull. Seismol. Soc. Am., 76, 1393-1405, 1986.

Yamanaka, H., K. Seo, and T. Samano, Analysis and numerical modeling of surface-wave propagation in a sedimentary basin, J. Phys. Earth, 40, 57-71, 1992.

Zama, S., Long-period strong ground motion, Zisin (J. Seismol. Soc. Jpn.), 46, 329-342, 1993 (in Japanese with English abstract). 